\title{
Pneumonia prevention in the elderly patients: the other sides
}

\author{
Najla Chebib ${ }^{1}$ - Clémence Cuvelier ${ }^{2}$ - Astrid Malézieux-Picard ${ }^{2}$ - Thibault Parent ${ }^{2} \cdot$ Xavier Roux $^{2,3} \cdot$ Thomas Fassier $^{2,4}$. \\ Frauke Müller ${ }^{1} \cdot$ Virginie Prendki $^{2,4,5}$
}

Received: 18 May 2019 / Accepted: 3 December 2019 / Published online: 31 December 2019

(c) Springer Nature Switzerland AG 2019, corrected publication 2020

\begin{abstract}
Pneumonia is one of the leading causes of morbidity and mortality from infection in elderly patients. The increased frequency of pneumonia among elderly subjects can be explained by the physiological changes linked to the progressive aging of the respiratory tree and the diminished immunological response. A spiral of event leads to frailty, infection and possible death; preventing pneumonia consists of controlling the risk factors. Dysphagia, which is associated with malnutrition and dehydration, is recognized as one of the major pathophysiological mechanism leading to pneumonia and its screening is crucial for the pneumonia risk assessment. The impairment in the oropharyngeal reflexes results in stagnation of foreign material in the lateral cavities of the pharynx which may then get aspirated repeatedly in the lungs and cause pneumonia. Pneumonia prevention starts with lifestyle modifications such as alcohol and tobacco cessation. A careful review of the risk-benefit of the prescribed medication is critical and adaptation may be required in elders with multiple morbidities. Respiratory physiotherapy and mobilization improve the functional status and hence may help reduce the risk of pneumonia. Maintaining teeth and masticatory efficiency is important if malnutrition and its consequences are to be avoided. Daily oral hygiene and regular professional removal of oral biofilm can prevent the onset of periodontitis and can avoid an oral environment favoring the colonization of respiratory pathogens than can then be aspirated into the lungs.
\end{abstract}

Keywords Pneumonia $\cdot$ Prevention $\cdot$ Aged over $80 \cdot$ Oral hygiene $\cdot$ Nutrition $\cdot$ Dysphagia

\section{Introduction}

Pneumonia is one of the leading causes of morbidity and mortality from infection in elderly patients [1]. The incidence of community-acquired pneumonia (CAP) is approximately 3 episodes/ 1000 persons in those aged between 65

Virginie Prendki

virginie.prendki@hcuge.ch

1 Division of Gerodontology and Removable Prosthodontics, University Clinics of Dental Medicine, University

of Geneva, Geneva, Switzerland

2 Division of Internal Medicine of the Aged, Department of Internal Medicine, Rehabilitation and Geriatrics, Geneva University Hospitals, University of Geneva, Geneva, Switzerland

3 Department of Anesthesiology, Pharmacology and Intensive Care, Geneva University Hospitals, Geneva, Switzerland

4 Faculty of Medicine, University of Geneva, Geneva, Switzerland

5 Hôpital des Trois-Chêne, Chemin du Pont-Bochet 3, 1226 Thônex-Genève, Switzerland and 69 years and increases to $22 / 1000$ persons between the ages of 85 and 89 years [2]. Clinical pneumonia resulted in 6.8 million hospitalizations worldwide and about in $1.1 \mathrm{mil}-$ lion in-hospital deaths occurred among them in 2015. The hospital admission rate was increased with age and higher in men [3].

The diagnosis of pneumonia is based on respiratory clinical symptoms such as cough, dyspnea and fever and the presence of a new infiltrate on the chest X-ray. In the elderly, the diagnosis is more complex due to age-related atypical symptoms, like for example, lowering of the temperature threshold. Patients often present to the emergency for falls or with a simultaneous decompensation of comorbidities [4, 5]. A good-quality chest X-ray is often difficult to perform and to interpret in $\geq 65$ years old, and the low-dose computed tomography proved to be a more adequate tool for diagnosing pneumonia in the elderly population [6].

Prognosis largely depends on comorbidities such as chronic heart failure, chronic respiratory diseases, neurological diseases, level of dependence, nutritional and cognitive status of the patient $[7,8]$. Functional status is an 
independent predictor for short- and long-term mortality in patients hospitalized for CAP and is associated with a risk of recurrent pneumonia in the elderly [9]. Comorbidities increase the risk of CAP by two-to-fourfold. The more frequent ones are: cardiovascular and chronic respiratory diseases, cerebrovascular and neurodegenerative diseases such as dementia and Parkinson's disease, chronic renal or liver disease and immunosuppression [10]. A summary of the effect of morbidities on the risk of CAP is presented in Table 1.

Mortality varies between 5 and $15 \%$ in hospitalized patients to $30-50 \%$ in intensive care unit patients. In addition, mortality is increased not only during the first months, but also in the years following pneumonia, partly related to an increase in cardiovascular events [11].

Given the high incidence of mortality, pneumonia prevention is particularly relevant in elderly patients. Vaccination is the most effective and known preventive measure and will be treated in another article of this issue. The objectives of this review are to summarize relevant information regarding the particularities of pneumonia in the elderly and its predisposing factors, and to provide an overview of the preventive measures other than vaccination for the elderly population.

\section{Pneumonia: etiology and pathophysiology}

Pneumonia is an inflammatory condition of the lung affecting primarily the alveoli. It is most commonly caused by bacteria, but the implication of viruses is now recognized [12]. The etiological agent is rarely identified, especially in elders [13]. In healthy individuals, bacterial density in the lower airways is defined by a constant exchange from the upper respiratory tract and oral microbiota by microaspiration, and retrograde clearance by respiratory epithelium cilia and cough [14]. An imbalance to this system

Table 1 Chronic diseases and their effect on pneumonia onset (according to Torres et al. 2013)

\begin{tabular}{ll}
\hline Morbidities & Risk of CAP \\
\hline Chronic cardiovascular disease & $3 \times$ the risk \\
Chronic respiratory disease & 2 to $4 \times$ the risk \\
$\begin{array}{l}\text { Neurological disease (cerebrovascular disease or } \\
\text { stroke, and neurodegenerative disease) }\end{array}$ & $2 \times$ the risk \\
Chronic renal disease & $2 \times$ the risk \\
Chronic liver disease & $2 \times$ the risk \\
Diabetes mellitus & Moderate risk \\
Cancer & Moderate risk \\
Immunosuppression: asplenia, HIV & $2 \times$ the risk \\
Rheumatoid arthritis & Moderate risk \\
Previous pneumonia & Moderate risk \\
\hline
\end{tabular}

occurs in case of host immunodeficiency, the presence of viral pathogens, or a significant bacterial inoculum which favors the development of pneumonia. Different mechanisms were proposed to how pathogens reach the lower respiratory tract. The inhalation of pathogens can give access to the lower respiratory tract, another major route is the aspiration of secretions from the oropharynx either directly or by reflux from the stomach [15]. A contiguous extension of a colonization/infection and the haematogenous carriage can also lead to pneumonia [16]. Pneumonia is often classified in relation to where it was acquired: community-acquired pneumonia (CAP), nursing home-acquired pneumonia (NHAP), hospital-acquired pneumonia (HAP) or ventilator-associated pneumonia (VAP) have been described. HAP is defined as pneumonia which manifests $48 \mathrm{~h}$ or more after admission to hospital, and VAP generally occurs more than $48-72 \mathrm{~h}$ after endotracheal intubation. Healthcare-acquired pneumonia (HCAP) occurs in patients with frequent contact with the health system, numerous antibiotic intake and/or a functional state of frailty $[17,18]$.

Pneumonia is also classified by its physio-pathological mechanism (i.e., aspiration pneumonia) or, if identified, by the etiological pathogen [15]. Jain et al. showed that the presence of influenza and $S$. pneumoniae was five times higher in pneumonia patients older than 65 years when compared to younger ones, and rhinovirus presence was ten times higher [12]. Obtaining high-quality samples is difficult with older patients and only $6 \%$ could provide high-quality sputum [13]. Comprehensive molecular testing performed in nasopharyngeal and oropharyngeal swabs is poorly predictive of the presence of pneumonia and proved less sensitive than routine microbiological methods for old patients in a cohort of 199 with a mean age of 83 years [19]. In a review of 33 studies published between January 2005 and July 2012 and focusing on the etiology and treatment of CAP among adults in Europe, Torres et al. concluded that Streptococcus pneumoniae, Haemophilus influenzae and respiratory viruses were the most frequently observed pathogens, and that Mycoplasma pneumoniae was less frequently found among patients $\geq 65$ years old [20]. General hygiene measures as contact and droplet precaution and use of masks are necessary tools to tackle global respiratory infections, among which viral infections [21].

\section{Dysphagia and malnutrition}

The high frequency of pneumonia among elderly subjects can be explained by the physiological changes linked to the progressive decline of the respiratory tree. The mucociliary clearance and the coughing reflexes are reduced leading to a poor airway clearance. Furthermore, the mobility of the oropharynx is often impaired resulting in swallowing 
problems. The immunosenescence involves alterations to the innate and adaptive immune systems favoring infections after broncho-aspirations [22, 23]. Oropharyngeal dysphagia (OD) is recognized as one of the major pathophysiological mechanisms leading to aspiration pneumonia in the elders $[15,24]$. Swallowing disorders or dysphagia affects 30-40\% of the population over 65 years with a prevalence of $75 \%$ in stroke patients, $82 \%$ in patients with neurodegenerative disease such as Parkinson's disease or $84 \%$ with dementia [25]. Dysphagia is also prevalent in $30 \%$ of independently living older adults and is independently associated with malnutrition in population of elders with a mean age 82 years [26]. Malnutrition (evaluated by mini nutritional assessment, body mass index (BMI) and serum albumin levels) is also highly prevalent and strongly associated with OD in older patients hospitalized for an acute disease [27]. Neurological diseases, incompetent lip closure, tongue protrusion and poor buccinators muscle strength induce poor masticatory ability, frequently associated with a decreased BMI and serum albumin concentrations [28]. The preparation of a food bolus can be impaired following the loss of teeth, which increases the risk of macro-aspiration into the airways [29]. The loss of masticatory efficiency changes food selection towards decreased consumption of vegetables, fruits, proteins, minerals and vitamins [30]. This poor nutritional intake worsens the decrease of lean muscular mass that occurs naturally with age and aggravates sarcopenia [31]. Moreover, dysphagia patients are often dehydrated because of a reduced sensation of thirst, or the fear of aspiration during drinking, potentially leading to oral dryness. Oral dryness favors oropharyngeal bacterial colonization [25]. The impaired swallowing efficacy often causes the stagnation of foreign material in the lateral cavities of the pharynx which may then get aspirated in the lungs when patients are placed in supine position [25]. Aspiration is often clinically silent because of impaired cough reflexes [32]. Having a low BMI is a predictor for a poor outcome for pneumonia in elder patients hospitalized or in intensive care [8]. For the very old patients aged over 85 years who are hospitalized for CAP, nutritional parameters at admission such as serum protein and albumin are associated with a decreased likelihood of death [7]. Malnutrition is independently associated with 30-day mortality in HAP in nursing home residents [33].

A seated position with the head-up by approximately $30^{\circ}$, during the day and at night, may reduce gastroesophageal regurgitation-associated aspiration [34]. Percutaneous endoscopic gastrostomy which is often performed in case of bronchoaspiration did not decrease its incidence when compared to patients fed with a nasogastric tube [35].

In acute stroke patient who are particularly at risk of pneumonia because of swallowing disorders and an altered mental status, antibiotic prophylaxis is sometimes prescribed for pneumonia prevention. Nevertheless, a recent cluster-randomized trial showed the absence of benefit of antibiotic prophylaxis in patients with dysphagia after stoke and hospitalized in stroke units [36].

\section{Lifestyle-related risk factors}

Along with the aging of the global population, the number of smokers aged 65 years or more is increasing worldwide. A recent study in Europe estimated their prevalence to be $11.5 \%$ as of 2010 [37]. Their mortality is doubled when compared to non-smokers [38]. Smokers, former smokers and passive smokers have an increased risk of CAP [10,39]. Former and current smokers have an increased mortality due to infectious diseases in general, and current heavy smoking (> 20 cigarettes/days) is a strong risk factor for pneumonia $(\mathrm{HR}=3.30)$ [40]. Current smoking increases the 30-day mortality in pneumococcal CAP versus non-smokers and ex-smokers [41]. Tobacco smoking plays an indirect role by causing chronic obstructive pulmonary disease (COPD), which is also recognized as a CAP risk factor [42]. Smoking cessation decreases the risk of CAP when compared to current smokers, but the time free from tobacco required to achieve a decreased CAP risk is long ( $>10$ year) [43]. Moreover, the risk is only decreased if the former smoker does not present with COPD [44]. For old passive smokers, the risk of CAP is also increased when compared to non-exposed persons (OR 1.59) when exposed to smoke for extended periods [39]. Smoking cessation can increase life expectancy, with those quitting at younger age benefiting the most. Quitting at age 65 years increases the life expectancy 1.4-2 years for men and 2.7-3.7 years for women [45, 46].

Another risk factor for CAP relates to alcohol consumption, which is one of the leading causes of mortality worldwide [47]. Excessive alcohol ingestion is commonly linked with liver disease, but it is also an independent risk factor for CAP [10, 48, 49]. Drinkers have an 83\% increase in the risk of CAP when compared to non-drinkers. The effect is dose dependent and consuming 10-20 g of alcohol per day was linked to an $8 \%$ increase of acquiring CAP [50]. The severity of CAP and the frequency of pneumococcal pneumonia are higher in drinkers than in the general population [51]. For older drinkers, the CAP can result in a severe sepsis [52]. They tend to spend more time in the hospital for pneumonia and have a higher risk of in-hospital mortality when compared to non-drinkers [53]. Moreover, certain pneumococcal serotypes (serotypes 4,11A, and 19F) were more frequently associated with invasive pneumococcal pneumonia in alcohol abusers [48]. Alcohol intake disturbs the local lung immunological defenses by altering the mucociliary clearance and by diminishing neutrophil chemotaxis and alveolar macrophage functions. With chronic alcohol consumption, 
oxidative stress pathways interfere with the normal immune reaction, thus impairing pathogen clearance [54].

Environmental exposures are less-noticed risk factors for pneumonia but they are known to be involved in the pathogenesis of lung diseases. Even in older adults, the long-term exposure to nitrogen dioxide and fine particulate matter were associated with hospitalization for pneumonia [55].

\section{Medication}

Elderly patients have often several comorbidities requiring multiple drug prescription. Immunosuppressive therapy and oral steroids have been reported to be risk factors for pneumonia of which clinicians need to be aware when prescribing these drugs [56].

The risk of pneumonia with gastric-acid-suppressive drugs (proton-pump inhibitors (PPI) and Histamine 2 receptor antagonists) has also been reported in many studies as the acid suppression promotes an increase of gastric colonization by pathogens and consequently an alteration of the gut microbiome [57]. The risk seems to be even higher when the treatment has been only recently prescribed [58].

Inhaled corticosteroids (ICS) and antipsychotics (Aps) may increase also the risk of pneumonia and negatively impact on its clinical outcome $[59,60]$. ICS, recommended to prevent and treat COPD, lower the pulmonary host defense, hence reducing extracellular release of nitric oxide by alveolar macrophages and decreasing cytokine production [61]. Concerning the use of Aps, a systematic review suggested an increase in the risk for CAP [62], being highest during the early phase of treatment and being dose dependent [63]. The extrapyramidal adverse effect could explain the increased risk for aspiration pneumonia. The anticholinergic side effects of Aps induce dryness of the mouth hence poor bolus preparation and transport. The sedative and anticholinergic side effects of Aps decrease the peristalsis resulting in an increased risk of aspirations [63]. The current use ( $<90$ days) of benzodiazepine receptor agonists is associated with hospitalization for pneumonia occurrence and is dose dependent, the risk of hospitalization from benzodiazepine hypnotic agents was higher than non-hypnotic and anxiolytic agents. Midazolam was found to increase almost five times the risk of hospitalization for pneumonia. Shortand intermediate-acting benzodiazepine receptor agonists increased the risk more than long-acting agents. [64]. The risk of pneumonia was also increased with non-hypnotic benzodiazepine in older adults [65]. The muscarinics- 1 and histaminergic-1 effects cause esophageal dilation and hypomotility in addition to sedation thus explaining the increased risk for pneumonia infection [66].

The susceptibility to pneumonia is increased among patients with diabetes and could be associated to antidiabetic drugs as thiazolinediones, which have immunomodulatory and glucocorticoid-like properties [67]. Nevertheless, the evidence is conflicting and large epidemiological studies are needed to confirm the association of antidiabetic drugs with the incidence of pneumonia [68-70].

On the other side, some medications were reported to have a protective effect on the occurrence of pneumonia. A meta-analysis supported the hypothesis that statins may reduce the risk of pneumonia but the quality of the currently available scientific evidence is unfortunately very low [71].

There is conflicting information on the protective effect of angiotensin II receptor blockers (ARB), and angiotensinconverting enzyme inhibitors (ACE) on the incidence of pneumonia. ARB and ACE were shown to decrease the risk of pneumonia in old hypertensive patients with Parkinson's disease and in post-stroke patients with aspiration pneumonia [72, 73].The possible explanation for the action of statins, ARB and ACE would be a modulatory effect in the inflammatory state by altering the production of proinflammatory cytokines, improving endothelial and mitochondrial dysfunction and to decreasing the reactive oxidative species [74]. Another mechanism of ACE would be an increase of substance $\mathrm{P}$ levels in the airways and plasma, improving swallowing function and cough reflexes [75].

Amantadine was found to have a beneficial effect on the risk of pneumonia in patients with a history of stroke, the dopamine supplementation improved the swallowing reflexes thus reducing by $20 \%$ the pneumonia risk [76].

More evidence from well-designed trials is needed to assess the link between therapeutic drugs and the risk of pneumonia, but at any rate, clinicians need to be particularly cautious when treating elders with multiple morbidity who take already multiple prescribed medications. The adequate policy for elders is to minimize prescriptions and potentially stop inappropriate ones [77].

\section{Physiotherapy}

Physiotherapy is not commonly suggested as prevention of pneumonia [78], although poor functional status is considered a risk factor for recurrent CAP [9]. The loss of muscle mass is an independent predictive factor of 3-month mortality in patients hospitalized for aspiration pneumonia [79]. In functionally unimpaired older adults, the development of a mobility limitation increases the risk of developing pneumonia [80]. Hence, two physiotherapeutic novel approaches could modify the pneumonia risk. The first concerns respiratory physiotherapy, which consists in guiding the patient into performing deep breathing exercises, coordinated breathing. The assisted cough helps the patient clear the secretions. It was shown that non-invasive ventilation and continuous positive airway pressure used prior to abdominal high-risk 
elective surgeries reduce the risk of post-operative pulmonary complication such as pneumonia and atelectasis [81]. Preoperative inspiratory muscle training in adults undergoing cardiac and major abdominal surgery decreases the post-operative pulmonary complications and reduces the length of hospital stay [82-84]. A pulmonary rehabilitation program initiated on the day following surgery showed a reduction in the incidence of pneumonia in elderly patients treated for hip fracture [85]. Moreover, early rehabilitation reduced the 30-day in-hospital mortality in geriatric patients with aspiration pneumonia [86].

The second approach is the mobilization physiotherapy; it targets mobility rather than chest function; it is well documented in post-operative care. The mobilization protocols are not structured and standardized and their effectiveness is still questionable, but mobilization reduces nevertheless the risk of complications associated with bed rest [87]. In a post-operative context, early mobilization and respiratory physiotherapy are associated with a decrease in pneumonia incidence and respiratory complications [88].

Among medical patients, early mobilization reduced the incidence of HAP with a hazard ratio of 0.39 , it also reduced the length of stay in hospital [89]. Including an inpatient exercise-based rehabilitation program improves the functional status of the patient as well as quality of life but may not have a direct impact on pulmonary function or the length of hospitalization [90].

\section{Oral health}

A natural dentition can be a major advantage in term of retaining the masticatory capabilities and chewing muscle bulk. Nevertheless, keeping one's natural teeth can become more challenging when physical limitations occur, as poor oral hygiene fosters the accumulation of dental plaque, a bacterial biofilm adhering to the teeth [91]. Patients having more than ten natural teeth and periodontal pocket depths of more than $4 \mathrm{~mm}$ presented an increased mortality due to pneumonia than those with periodontal pockets smaller than $4 \mathrm{~mm}[92,93]$. The quantity of periodontal bacteria in 85-year-old persons increases with the number of teeth [94]. Broncho-alveolar lavage samples from patients admitted to the hospital with clinical symptoms of pneumonia have confirmed the involvement of oral microorganism [95]. Anaerobic germs (Veillonella sp. and Porphyromonas gingivalis) implicated in periodontal disease were found in dentate patients as well as a high concentration of Staphylococcus aureus in patients wearing prosthetic appliances [95].

Periodontal disease leads to an increase in the mass and the diversity of the microbiota causing the destruction of the tissues surrounding the teeth [96]. It prompts a true immune response of the host with triggering of the inflammatory cascade, various signaling molecules are implicated, i.e. cytokines, the cytokines secreted into mucosal saliva may promote adhesion and colonization by respiratory pathogens such as Pseudomonas aeruginosa and enteric bacilli [97]. Ortega et al. showed that oral colonization by respiratory pathogens was more common in frail patients with oral dysphagia (with or without pneumonia) than in healthy subjects without dysphagia (93\% vs. 67\%) [98]. Hence, the oral biofilm constitutes a likely reservoir for pulmonary pathogens [99-103]. It has also been suggested that an imbalanced oropharyngeal microbiota reduces colonization resistance allowing pathogens to spread [104]. Elderly pneumonia patients presented a higher proportion of some Streptococcus species and Rothia, whereas Gemellales, Prevotella, Veillonella dispar, Parascardovia and Leptotrichia had lower relative abundance compared to non-pneumonia controls. An age-related decrease in anaerobic colonization (Prevotella, Veillonella, Leptotrichia) increased the susceptibility to pneumonia. Bacterial diversity (expressed as Shannon diversity index) and bacterial load of oropharyngeal microbiota were increased in elderly pneumonia patients in comparison to elderly without pneumonia [104].

These cytokines produced at high levels in gingival fluid and serum are in contact with respiratory epithelial cells via the hematogenous route. This inflammatory event can lead to epithelial and endothelial injury that increases susceptibility to infections; they were shown to result in a shift from a diverse microbiota in the lungs to a dominance by single species such as Streptococcus pneumonia and Pseudomonas aeruginosa [105].

A systematic review conducted in 2008 analyzed the link between oral hygiene and the risk of pneumonia and concluded that one in ten deaths could be avoided in elders living in institutions through adequate and regular dental hygiene [106]. However, according to the authors, the mechanical cleaning of the teeth should be done by dental professionals, such as hygienists or dentists, because the risk of pneumonia was unchanged when hygiene was provided by the nursing or auxiliary staff [107].

Tongue coating is also associated with a higher bacteria count in the saliva and the development of aspiration pneumonia [108]. Furthermore, patients wearing removable dentures at night were more likely to develop pneumonia than those removing it before bedtime [109]. The dentists' current recommendation is to remove dentures at night to prevent oral candidiasis promoting bacterial superinfection and to keep them dry or in a disinfectant bath [110-112].

Chlorhexidine mouthwashes significantly reduce bacterial colonization in elders [113]. However, chlorhexidine is an adjuvant and cannot replace mechanical cleaning or brushing because its chemical efficacy against bacterial biofilm is limited. Thus, concentrations of $0.12-0.2 \%$ can be used, an initial debridement of dental plaque is still necessary [114]. 
Table 2 Overview of pneumonia preventive measures (adapted from Prina et al. 2015)

\begin{tabular}{|c|c|}
\hline Risk factor & Recommendation \\
\hline \multicolumn{2}{|l|}{ Patient status } \\
\hline Old age & Vaccination against $H$. influenza and $S$. pneumonia \\
\hline Swallowing disorder & Thicken liquids, small bolus, adjust head position \\
\hline Hyposalivation & Chewing of gum, oral moisturizers \\
\hline Malnutrition & Food supplements, adjustment of diet, assuring chewing efficiency \\
\hline \multirow[t]{2}{*}{ Physical frailty } & Physiotherapy \\
\hline & CPAP prior to surgery and preoperative training \\
\hline \multicolumn{2}{|l|}{ Environment } \\
\hline Environmental exposure & Limit exposure to nitrogen dioxide and fine particulate matter \\
\hline $\begin{array}{l}\text { Living in a nursing home or frequently exposed to } \\
\text { healthcare environment }\end{array}$ & Favor home care when possible \\
\hline \multicolumn{2}{|l|}{ Habits } \\
\hline Smoking & Smoking cessation \\
\hline Alcohol & Adjust alcohol consumption \\
\hline \multicolumn{2}{|l|}{ Medications } \\
\hline Immunosuppressive drugs and oral steroids & Monitor carefully when used and adjust if possible \\
\hline $\mathrm{PPI}$ and $\mathrm{H} 2$ receptor antagonists & Monitor carefully when used and adjust if possible \\
\hline Inhaled corticosteroids & Monitor carefully when used and adjust if possible \\
\hline Antipsychotics & Monitor salivary flow and in case of hyposalivation treat xerostomia \\
\hline Benzodiazepine & Check level of sedation and adjust where necessary \\
\hline Statin & Prescribe when indicated, as it may reduce the risk of pneumonia \\
\hline ACE inhibitors and ARB's & Prescribe when indicated, as it may reduce the risk of pneumonia in Parkinson patients \\
\hline Amantadine & Prescribe when indicated, as it may reduce the risk of pneumonia in stroke patients \\
\hline \multicolumn{2}{|l|}{ Oral health } \\
\hline Oral hypofunction & Regular dental check-up visits and treatment where indicated \\
\hline Poor oral hygiene & Daily oral hygiene in addition to regular oral hygiene provided by dental hygienist \\
\hline Poor tongue hygiene & Use of tongue scrapping \\
\hline Dental prosthesis & Assure denture hygiene and remove denture during sleep \\
\hline
\end{tabular}

$C P A P$ continuous positive airway pressure, $P P I$ proton-pump inhibitors, $H 2$ histamine 2 receptor antagonist, $A C E$ inhibitors angiotensin-converting enzyme inhibitors, $A R B$ angiotensin II receptor blockers

A recent systematic review evaluated the effect of oral care measures for residents in nursing homes and long-term facilities. The analysis was unable to confirm that professional oral care resulted in a lower incidence of NHAP or reduced the risk of pneumonia associated mortality. The authors concluded that professional oral care or oral care measures may reduce mortality due to pneumonia but the level of evidence is still insufficient [115].

An overview of suggested preventive measures than can be undertaken to control the risk factors for pneumonia in the elderly is presented in Table 2 .

\section{Conclusion}

While the vaccine remains the best known and best studied pneumonia prevention strategy, it is important to recognize the modifiable risk factors that are related to the onset of pneumonia. Dysphagia is a major risk factor for pneumonia, its screening and management is also important to prevent malnutrition, dehydration and xerostomia. Controlling lifestyle related risk factors such as smoking, and alcohol consumption could decrease the risk of pneumonia, even in elderly patients. A careful review of the prescribed medications and a close monitoring of side effects can also reduce the risk of pneumonia. Maintaining teeth and thus chewing muscle mass can improve oral function, nutritional and functional status. Simple everyday practices such as oral biofilm removal or removing the denture before bedtime are easy to implement and efficient measures to reduce the risk of pneumonia.

Acknowledgements The contribution of the ESCMID Study Group for Infections in the Elderly (ESGIE; http://www.escmid.org/esgie) to this study is also acknowledged. 
Funding VP received grants from the Geneva University Hospitals (HUG) (Research \& Development Grant, Medical Directorate, HUG and Research Fund of the Department of Internal Medicine of the University Hospital and the Faculty of Medicine of Geneva) and the Ligue Pulmonaire Genevoise, a non-profit association involved in the care of patients with respiratory diseases.

\section{Compliance with ethical standards}

Conflict of interest The authors declare no conflict of interest. The funders had no role in the design of the study, in the collection, analyses, or interpretation of data, in the writing of the manuscript, or in the decision to publish the results.

Ethical approval This article does not contain any studies with human participants or animals performed by any of the authors.

Informed consent No informed consent was needed for this article.

\section{References}

1. Collaborators GL (2017) Estimates of the global, regional, and national morbidity, mortality, and aetiologies of lower respiratory tract infections in 195 countries: a systematic analysis for the Global Burden of Disease Study 2015. Lancet Infect Dis 17:1133-1161. https://doi.org/10.1016/S1473-3099(17)30396-1

2. Millett ER, Quint JK, Smeeth L et al (2013) Incidence of community-acquired lower respiratory tract infections and pneumonia among older adults in the United Kingdom: a populationbased study. PLoS One 8:e75131. https://doi.org/10.1371/journ al.pone. 0075131

3. Shi T, Denouel A, Tietjen AK et al (2019) Global and regional burden of hospital admissions for pneumonia in older adults: a systematic review and meta-analysis. J Infect Dis. https://doi. org/10.1093/infdis/jiz053

4. Fernandez-Sabe N, Carratala J, Roson B et al (2003) Community-acquired pneumonia in very elderly patients: causative organisms, clinical characteristics, and outcomes. Medicine (Baltimore) 82:159-169. https://doi.org/10.1097/01.md.00000 76005.64510 .87

5. Black AD (2016) Non-infectious mimics of community-acquired pneumonia. Pneumonia (Nathan) 8:2. https://doi.org/10.1186/ s41479-016-0002-1

6. Prendki V, Scheffler M, Huttner B et al (2018) Low-dose computed tomography for the diagnosis of pneumonia in elderly patients: a prospective, interventional cohort study. Eur Respir J. https://doi.org/10.1183/13993003.02375-2017

7. Calle A, Marquez MA, Arellano M et al (2014) Geriatric assessment and prognostic factors of mortality in very elderly patients with community-acquired pneumonia. Arch Bronconeumol 50:429-434. https://doi.org/10.1016/j.arbres.2014.01.012

8. Bo M, Massaia M, Raspo S et al (2003) Predictive factors of inhospital mortality in older patients admitted to a medical intensive care unit. J Am Geriatr Soc 51:529-533. https://doi.org/10. 1046/j.1532-5415.2003.51163.x

9. Dang TT, Eurich DT, Weir DL et al (2014) Rates and risk factors for recurrent pneumonia in patients hospitalized with community-acquired pneumonia: population-based prospective cohort study with 5 years of follow-up. Clin Infect Dis 59:74-80. https ://doi.org/10.1093/cid/ciu247

10. Torres A, Peetermans WE, Viegi G et al (2013) Risk factors for community-acquired pneumonia in adults in Europe: a literature review. Thorax 68:1057-1065. https://doi.org/10.1136/thoraxjnl2013-204282

11. Corrales-Medina VF, Alvarez KN, Weissfeld LA et al (2015) Association between hospitalization for pneumonia and subsequent risk of cardiovascular disease. JAMA 313:264-274. https ://doi.org/10.1001/jama.2014.18229

12. Jain S, Self WH, Wunderink RG et al (2015) Communityacquired pneumonia requiring hospitalization among US adults. N Engl J Med 373:415-427. https://doi.org/10.1056/ nejmoa 1500245

13. Musher DM, Abers MS, Bartlett JG (2017) Evolving understanding of the causes of pneumonia in adults, with special attention to the role of pneumococcus. Clin Infect Dis 65:1736-1744. https://doi.org/10.1093/cid/cix549

14. Dickson RP, Erb-Downward JR, Huffnagle GB (2014) Towards an ecology of the lung: new conceptual models of pulmonary microbiology and pneumonia pathogenesis. Lancet Respir Med 2:238-246. https://doi.org/10.1016/s2213-2600(14)70028-1

15. Mandell LA, Niederman MS (2019) Aspiration pneumonia. N Engl J Med 380:651-663. https://doi.org/10.1056/NEJMr a1714562

16. Pirracchio R, Mateo J, Raskine L et al (2009) Can bacteriological upper airway samples obtained at intensive care unit admission guide empiric antibiotherapy for ventilator-associated pneumonia? Crit Care Med 37:2559-2563. https://doi. org/10.1097/CCM.0b013e3181a57b48

17. Mandell LA, Wunderink RG, Anzueto A et al (2007) Infectious diseases Society of America/American Thoracic Society consensus guidelines on the management of community-acquired pneumonia in adults. Clin Infect Dis 44:S27-S72. https://doi. org/10.1086/511159

18. Torres A, Niederman MS, Chastre J et al (2017) International ERS/ESICM/ESCMID/ALAT guidelines for the management of hospital-acquired pneumonia and ventilator-associated pneumonia: Guidelines for the management of hospitalacquired pneumonia (HAP)/ventilator-associated pneumonia (VAP) of the European Respiratory Society (ERS), European Society of Intensive Care Medicine (ESICM), European Society of Clinical Microbiology and Infectious Diseases (ESCMID) and Asociacion Latinoamericana del Torax (ALAT). Eur Respir J. https://doi.org/10.1183/13993003.00582-2017

19. Prendki V, Huttner B, Marti C et al (2019) Accuracy of comprehensive PCR analysis of nasopharyngeal and oropharyngeal swabs for CT-scan-confirmed pneumonia in elderly patients: a prospective cohort study. Clin Microbiol Infect. https://doi. org/10.1016/j.cmi.2018.12.037

20. Torres A, Blasi F, Peetermans WE et al (2014) The aetiology and antibiotic management of community-acquired pneumonia in adults in Europe: a literature review. Eur J Clin Microbiol Infect Dis 33:1065-1079. https://doi.org/10.1007/s1009 6-014-2067-1

21. Pagani L, Thomas Y, Huttner B et al (2015) Transmission and effect of multiple clusters of seasonal influenza in a Swiss geriatric hospital. J Am Geriatr Soc 63:739-744. https://doi. org/10.1111/jgs.13339

22. Janssens JP (2005) Pneumonia in the elderly (geriatric) population. Curr Opin Pulm Med 11:226-230. https://doi. org/10.1097/01.mcp.0000158254.90483.1f

23. Krone CL, van de Groep K, Trzcinski K et al (2014) Immunosenescence and pneumococcal disease: an imbalance in hostpathogen interactions. Lancet Respir Med 2:141-153. https://doi. org/10.1016/s2213-2600(13)70165-6

24. Marik PE, Kaplan D (2003) Aspiration pneumonia and dysphagia in the elderly. Chest 124:328-336. https://doi.org/10.1378/chest .124 .1 .328 
25. Clave P, Shaker R (2015) Dysphagia: current reality and scope of the problem. Nat Rev Gastroenterol Hepatol 12:259-270. https ://doi.org/10.1038/nrgastro.2015.49

26. Tagliaferri S, Lauretani F, Pela G et al (2018) The risk of dysphagia is associated with malnutrition and poor functional outcomes in a large population of outpatient older individuals. Clin Nutr. https://doi.org/10.1016/j.clnu.2018.11.022

27. Carrion S, Roca M, Costa A et al (2017) Nutritional status of older patients with oropharyngeal dysphagia in a chronic versus an acute clinical situation. Clin Nutr 36:1110-1116. https://doi. org/10.1016/j.clnu.2016.07.009

28. Mojon P, Budtz-Jorgensen E, Rapin CH (1999) Relationship between oral health and nutrition in very old people. Age Ageing 28:463-468. https://doi.org/10.1093/ageing/28.5.463

29. Okamoto N, Tomioka K, Saeki K et al (2012) Relationship between swallowing problems and tooth loss in community-dwelling independent elderly adults: the Fujiwara-kyo study. J Am Geriatr Soc 60:849-853. https://doi.org/10.111 1/j.1532-5415.2012.03935.x

30. Savoca MR, Arcury TA, Leng X et al (2010) Food avoidance and food modification practices due to oral health problems linked to the dietary quality of older adults. J Am Geriatr Soc 58:12251232. https://doi.org/10.1111/j.1532-5415.2010.02909.x

31. Frontera WR, Zayas AR, Rodriguez N (2012) Aging of human muscle: understanding sarcopenia at the single muscle cell level. Phys Med Rehabil Clin N Am 23:201-207. https://doi. org/10.1016/j.pmr.2011.11.012

32. Teramoto S, Fukuchi Y, Sasaki H et al (2008) High incidence of aspiration pneumonia in community- and hospital-acquired pneumonia in hospitalized patients: a multicenter, prospective study in Japan. J Am Geriatr Soc 56:577-579. https://doi.org/10 $.1111 /$ j.1532-5415.2008.01597.x

33. Falcone M, Russo A, Gentiloni Silverj F et al (2018) Predictors of mortality in nursing-home residents with pneumonia: a multicentre study. Clin Microbiol Infect 24:72-77. https://doi. org/10.1016/j.cmi.2017.05.023

34. Matsui T, Yamaya M, Ohrui T et al (2002) Sitting position to prevent aspiration in bed-bound patients. Gerontology 48:194-195. https://doi.org/10.1159/000052841

35. Gomes CA, Andriolo RB, Bennett C et al (2015) Percutaneous endoscopic gastrostomy versus nasogastric tube feeding for adults with swallowing disturbances. Cochrane Database Syst Rev. https://doi.org/10.1002/14651858.cd008096.pub4

36. Kalra L, Irshad S, Hodsoll J et al (2015) Prophylactic antibiotics after acute stroke for reducing pneumonia in patients with dysphagia (STROKE-INF): a prospective, cluster-randomised, open-label, masked endpoint, controlled clinical trial. Lancet 386:1835-1844. https://doi.org/10.1016/s0140-6736(15)00126-9

37. Lugo A, La Vecchia C, Boccia S et al (2013) Patterns of smoking prevalence among the elderly in Europe. Int J Environ Res Public Health 10:4418-4431. https://doi.org/10.3390/ijerph10094418

38. LaCroix AZ, Lang J, Scherr P et al (1991) Smoking and mortality among older men and women in three communities. N Engl J Med 324:1619-1625. https://doi.org/10.1056/nejm19910606324 2303

39. Almirall J, Serra-Prat M, Bolibar I et al (2014) Passive smoking at home is a risk factor for community-acquired pneumonia in older adults: a population-based case-control study. BMJ Open 4:e005133. https://doi.org/10.1136/bmjopen-2014-005133

40. Hamer M, O’Donovan G, Stamatakis E (2019) Lifestyle risk factors, obesity and infectious disease mortality in the general population: linkage study of 97,844 adults from England and Scotland. Prev Med 123:65-70. https://doi.org/10.1016/j.ypmed .2019 .03 .002
41. Bello S, Menendez R, Antoni T et al (2014) Tobacco smoking increases the risk for death from pneumococcal pneumonia. Chest 146:1029-1037. https://doi.org/10.1378/chest.13-2853

42. Braeken DC, Rohde GG, Franssen FM et al (2017) Risk of community-acquired pneumonia in chronic obstructive pulmonary disease stratified by smoking status: a population-based cohort study in the United Kingdom. Int J Chron Obstruct Pulmon Dis 12:2425-2432. https://doi.org/10.2147/copd.S138435

43. Baik I, Curhan GC, Rimm EB et al (2000) A prospective study of age and lifestyle factors in relation to community-acquired pneumonia in US men and women. Arch Intern Med 160:3082-3088

44. Cecere LM, Williams EC, Sun H et al (2012) Smoking cessation and the risk of hospitalization for pneumonia. Respir Med 106:1055-1062. https://doi.org/10.1016/j.rmed.2012.03.018

45. Jha P, Ramasundarahettige C, Landsman V et al (2013) 21st-century hazards of smoking and benefits of cessation in the United States. N Engl J Med 368:341-350. https://doi.org/10.1056/ NEJMsa1211128

46. Taylor DH Jr, Hasselblad V, Henley SJ et al (2002) Benefits of smoking cessation for longevity. Am J Public Health 92:990-996

47. Mokdad AH, Marks JS, Stroup DF et al (2004) Actual causes of death in the United States, 2000. JAMA 291:1238-1245. https ://doi.org/10.1001/jama.291.10.1238

48. Grau I, Ardanuy C, Calatayud L et al (2014) Smoking and alcohol abuse are the most preventable risk factors for invasive pneumonia and other pneumococcal infections. Int J Infect Dis 25:59-64. https://doi.org/10.1016/j.ijid.2013.12.013

49. Samokhvalov AV, Irving HM, Rehm J (2010) Alcohol consumption as a risk factor for pneumonia: a systematic review and meta-analysis. Epidemiol Infect 138:1789-1795. https://doi. org/10.1017/s0950268810000774

50. Simou E, Britton J, Leonardi-Bee J (2018) Alcohol and the risk of pneumonia: a systematic review and meta-analysis. BMJ Open 8:e022344. https://doi.org/10.1136/bmjopen-2018-022344

51. Bhatty M, Pruett SB, Swiatlo E et al (2011) Alcohol abuse and Streptococcus pneumoniae infections: consideration of virulence factors and impaired immune responses. Alcohol 45:523-539. https://doi.org/10.1016/j.alcohol.2011.02.305

52. Montull B, Menendez R, Torres A et al (2016) Predictors of severe sepsis among patients hospitalized for communityacquired pneumonia. PLoS One 11:e0145929. https://doi. org/10.1371/journal.pone.0145929

53. Gili-Miner M, Lopez-Mendez J, Bejar-Prado L et al (2015) Alcohol use disorders and community-acquired pneumococcal pneumonia: associated mortality, prolonged hospital stay and increased hospital spending. Arch Bronconeumol 51:564-570. https://doi.org/10.1016/j.arbres.2015.01.001

54. Yeligar SM, Chen MM, Kovacs EJ et al (2016) Alcohol and lung injury and immunity. Alcohol 55:51-59. https://doi. org/10.1016/j.alcohol.2016.08.005

55. Neupane B, Jerrett M, Burnett RT et al (2010) Long-term exposure to ambient air pollution and risk of hospitalization with community-acquired pneumonia in older adults. Am J Respir Crit Care Med 181:47-53. https://doi.org/10.1164/rccm.20090 1-0160OC

56. Jackson LA, Neuzil KM, Yu O et al (2003) Effectiveness of pneumococcal polysaccharide vaccine in older adults. N Engl J Med 348:1747-1755. https://doi.org/10.1056/NEJMoa022678

57. Marchina S, Doros G, Modak J et al (2019) Acid-suppressive medications and risk of pneumonia in acute stroke patients: a systematic review and meta-analysis. J Neurol Sci 400:122-128. https://doi.org/10.1016/j.jns.2019.02.041

58. Meijvis SC, Cornips MC, Voorn GP et al (2011) Microbial evaluation of proton-pump inhibitors and the risk of pneumonia. Eur 
Respir J 38:1165-1172. https://doi.org/10.1183/09031936.00020 811

59. Gau JT, Acharya U, Khan S et al (2010) Pharmacotherapy and the risk for community-acquired pneumonia. BMC Geriatr 10:45. https://doi.org/10.1186/1471-2318-10-45

60. Liapikou A, Cilloniz C, Torres A (2018) Drugs that increase the risk of community-acquired pneumonia: a narrative review. Expert Opin Drug Saf 17:991-1003. https://doi. org/10.1080/14740338.2018.1519545

61. Patterson CM, Morrison RL, D'Souza A et al (2012) Inhaled fluticasone propionate impairs pulmonary clearance of Klebsiella pneumoniae in mice. Respir Res 13:40. https://doi. org/10.1186/1465-9921-13-40

62. Nose M, Recla E, Trifiro G et al (2015) Antipsychotic drug exposure and risk of pneumonia: a systematic review and metaanalysis of observational studies. Pharmacoepidemiol Drug Saf 24:812-820. https://doi.org/10.1002/pds.3804

63. Trifiro G, Gambassi G, Sen EF et al (2010) Association of community-acquired pneumonia with antipsychotic drug use in elderly patients: a nested case-control study. Ann Intern Med 152:418-425. https://doi.org/10.7326/0003-4819-152-7-20100 4060-00006

64. Chen TY, Winkelman JW, Mao WC et al (2018) The use of benzodiazepine receptor agonists and the risk of hospitalization for pneumonia: a nationwide population-based nested casecontrol study. Chest 153:161-171. https://doi.org/10.1016/j. chest.2017.07.030

65. Jung S, Spence MM, Escasa NM et al (2016) The risk of pneumonia in older adults using nonbenzodiazepine hypnotics. J Manag Care Spec Pharm 22:932-938. https://doi.org/10.18553 /jmcp.2016.22.8.932

66. Maddalena AS, Fox M, Hofmann M et al (2004) Esophageal dysfunction on psychotropic medication A case report and literature review. Pharmacopsychiatry 37:134-138. https://doi. org/10.1055/s-2004-818993

67. Gorricho J, Garjon J, Alonso A et al (2017) Use of oral antidiabetic agents and risk of community-acquired pneumonia: a nested case-control study. Br J Clin Pharmacol 83:2034-2044. https://doi.org/10.1111/bcp.13288

68. Reinhold D, Biton A, Goihl A et al (2007) Dual inhibition of dipeptidyl peptidase IV and aminopeptidase N suppresses inflammatory immune responses. Ann N Y Acad Sci 1110:402-409. https://doi.org/10.1196/annals.1423.042

69. Lankas GR, Leiting B, Roy RS et al (2005) Dipeptidyl peptidase IV inhibition for the treatment of type 2 diabetes: potential importance of selectivity over dipeptidyl peptidases 8 and 9. Diabetes 54:2988-2994. https://doi.org/10.2337/diabe tes.54.10.2988

70. Willemen MJ, Mantel-Teeuwisse AK, Straus SM et al (2011) Use of dipeptidyl peptidase-4 inhibitors and the reporting of infections: a disproportionality analysis in the World health organization VigiBase. Diabetes Care 34:369-374. https://doi. org/10.2337/dc10-1771

71. Khan AR, Riaz M, Bin Abdulhak AA et al (2013) The role of statins in prevention and treatment of community acquired pneumonia: a systematic review and meta-analysis. PLoS One 8:e52929. https://doi.org/10.1371/journal.pone.0052929

72. Mortensen EM, Nakashima B, Cornell J et al (2012) Population-based study of statins, angiotensin II receptor blockers, and angiotensin-converting enzyme inhibitors on pneumoniarelated outcomes. Clin Infect Dis 55:1466-1473. https://doi. org/10.1093/cid/cis733

73. Kang JH, Kao LT, Lin HC et al (2018) Do outpatient statins and ACEIs/ARBs have synergistic effects in reducing the risk of pneumonia? A population-based case-control study. PLoS
One 13:e0199981. https://doi.org/10.1371/journal.pone.01999 81

74. Oesterle A, Laufs U, Liao JK (2017) Pleiotropic effects of statins on the cardiovascular system. Circ Res 120:229-243. https://doi. org/10.1161/circresaha.116.308537

75. Ikeda J, Kojima N, Saeki K et al (2015) Perindopril increases the swallowing reflex by inhibiting substance $\mathrm{P}$ degradation and tyrosine hydroxylase activation in a rat model of dysphagia. Eur J Pharmacol 746:126-131. https://doi.org/10.1016/j.ejpha r.2014.11.002

76. Nakagawa T, Wada H, Sekizawa K et al (1999) Amantadine and pneumonia. Lancet 353:1157. https://doi.org/10.1016/S0140 $-6736(98) 05805-\mathrm{X}$

77. Hill-Taylor B, Sketris I, Hayden J et al (2013) Application of the STOPP/START criteria: a systematic review of the prevalence of potentially inappropriate prescribing in older adults, and evidence of clinical, humanistic and economic impact. J Clin Pharm Ther 38:360-372. https://doi.org/10.1111/jcpt.12059

78. Prina E, Ranzani OT, Torres A (2015) Community-acquired pneumonia. Lancet 386:1097-1108. https://doi.org/10.1016/ s0140-6736(15)60733-4

79. Maeda K, Akagi J (2017) Muscle mass loss is a potential predictor of 90-day mortality in older adults with aspiration pneumonia. J Am Geriatr Soc 65:e18-e22. https://doi.org/10.1111/ jgs. 14543

80. Juthani-Mehta M, De Rekeneire N, Allore H et al (2013) Modifiable risk factors for pneumonia requiring hospitalization of community-dwelling older adults: the health, aging, and body composition study. J Am Geriatr Soc 61:1111-1118. https://doi. org/10.1111/jgs.12325

81. Lockstone J, Parry SM, Denehy L et al (2018) Physiotherapist administered, non-invasive ventilation to reduce postoperative pulmonary complications in high-risk patients following elective upper abdominal surgery; a before-and-after cohort implementation study. Physiotherapy. https://doi.org/10.1016/j.physi o.2018.12.003

82. Katsura M, Kuriyama A, Takeshima T et al (2015) Preoperative inspiratory muscle training for postoperative pulmonary complications in adults undergoing cardiac and major abdominal surgery. Cochrane Database Syst Rev. https://doi.org/10.1002/14651 858.cd010356.pub2

83. Boden I, El-Ansary D, Zalucki N et al (2018) Physiotherapy education and training prior to upper abdominal surgery is memorable and has high treatment fidelity: a nested mixed-methods randomised-controlled study. Physiotherapy 104:194-202. https ://doi.org/10.1016/j.physio.2017.08.008

84. Boden I, Skinner EH, Browning L et al (2018) Preoperative physiotherapy for the prevention of respiratory complications after upper abdominal surgery: pragmatic, double blinded, multicentre randomised controlled trial. BMJ 360:j5916. https://doi. org/10.1136/bmj.j5916

85. Chang SC, Lai JI, Lu MC et al (2018) Reduction in the incidence of pneumonia in elderly patients after hip fracture surgery: an inpatient pulmonary rehabilitation program. Medicine (Baltimore) $97:$ e11845. https://doi.org/10.1097/md.000000000001184 5

86. Momosaki R, Yasunaga H, Matsui H et al (2015) Effect of early rehabilitation by physical therapists on in-hospital mortality after aspiration pneumonia in the elderly. Arch Phys Med Rehabil 96:205-209. https://doi.org/10.1016/j.apmr.2014.09.014

87. Castelino T, Fiore JF Jr, Niculiseanu P et al (2016) The effect of early mobilization protocols on postoperative outcomes following abdominal and thoracic surgery: a systematic review. Surgery 159:991-1003. https://doi.org/10.1016/j.surg.2015.11.029

88. Haines KJ, Skinner EH, Berney S (2013) Association of postoperative pulmonary complications with delayed mobilisation 
following major abdominal surgery: an observational cohort study. Physiotherapy 99:119-125. https://doi.org/10.1016/j.physi o.2012.05.013

89. Stolbrink M, McGowan L, Saman H et al (2014) The early mobility bundle: a simple enhancement of therapy which may reduce incidence of hospital-acquired pneumonia and length of hospital stay. J Hosp Infect 88:34-39. https://doi.org/10.1016/j. jhin.2014.05.006

90. Jose A, Dal Corso S (2016) Inpatient rehabilitation improves functional capacity, peripheral muscle strength and quality of life in patients with community-acquired pneumonia: a randomised trial. J Physiother 62:96-102. https://doi.org/10.1016/j.jphys 2016.02.014

91. Peltola P, Vehkalahti MM, Wuolijoki-Saaristo K (2004) Oral health and treatment needs of the long-term hospitalised elderly. Gerodontology 21:93-99

92. Awano S, Ansai T, Takata Y et al (2008) Oral health and mortality risk from pneumonia in the elderly. J Dent Res 87:334-339. https://doi.org/10.1177/154405910808700418

93. Iwasaki M, Taylor GW, Awano S et al (2018) Periodontal disease and pneumonia mortality in haemodialysis patients: a 7-year cohort study. J Clin Periodontol 45:38-45. https://doi. org/10.1111/jcpe. 12828

94. Tachibana M, Yoshida A, Ansai T et al (2006) Prevalence of periodontopathic bacteria on the tongue dorsum of elderly people. Gerodontology 23:123-126. https://doi.org/10.111 1/j.1741-2358.2006.00116.x

95. Imsand M, Janssens JP, Auckenthaler R et al (2002) Bronchopneumonia and oral health in hospitalized older patients. A pilot study. Gerodontology 19:66-72

96. Mombelli A (2018) Microbial colonization of the periodontal pocket and its significance for periodontal therapy. Periodontol 2000 76:85-96. https://doi.org/10.1111/prd.12147

97. Scannapieco FA (1999) Role of oral bacteria in respiratory infection. J Periodontol 70:793-802. https://doi.org/10.1902/ jop.1999.70.7.793

98. Ortega O, Sakwinska O, Combremont $\mathrm{S}$ et al (2015) High prevalence of colonization of oral cavity by respiratory pathogens in frail older patients with oropharyngeal dysphagia. Neurogastroenterol Motil 27:1804-1816. https://doi.org/10.1111/nmo.12690

99. Fourrier F, Duvivier B, Boutigny H et al (1998) Colonization of dental plaque: a source of nosocomial infections in intensive care unit patients. Crit Care Med 26:301-308. https://doi. org/10.1097/00003246-199802000-00032

100. Russell SL, Boylan RJ, Kaslick RS et al (1999) Respiratory pathogen colonization of the dental plaque of institutionalized elders. Spec Care Dentist 19:128-134. https://doi. org/10.1111/j.1754-4505.1999.tb01413.x

101. El-Solh AA, Pietrantoni C, Bhat A et al (2004) Colonization of dental plaques: a reservoir of respiratory pathogens for hospitalacquired pneumonia in institutionalized elders. Chest 126:15751582. https://doi.org/10.1378/chest.126.5.1575

102. Souza LCD, Mota V, Carvalho A et al (2017) Association between pathogens from tracheal aspirate and oral biofilm of patients on mechanical ventilation. Braz Oral Res 31:e38. https ://doi.org/10.1590/1807-3107BOR-2017.vol31.0038
103. Hong C, Aung MM, Kanagasabai K et al (2018) The association between oral health status and respiratory pathogen colonization with pneumonia risk in institutionalized adults. Int J Dent Hyg 16:e96-e102. https://doi.org/10.1111/idh.12321

104. de Steenhuijsen Piters WA, Huijskens EG, Wyllie AL et al (2016) Dysbiosis of upper respiratory tract microbiota in elderly pneumonia patients. ISME J 10:97-108. https://doi.org/10.1038/ismej .2015 .99

105. Huffnagle GB, Dickson RP, Lukacs NW (2017) The respiratory tract microbiome and lung inflammation: a two-way street. Mucosal Immunol 10:299-306. https://doi.org/10.1038/ mi.2016.108

106. Sjogren P, Nilsson E, Forsell M et al (2008) A systematic review of the preventive effect of oral hygiene on pneumonia and respiratory tract infection in elderly people in hospitals and nursing homes: effect estimates and methodological quality of randomized controlled trials. J Am Geriatr Soc 56:2124-2130. https ://doi.org/10.1111/j.1532-5415.2008.01926.x

107. Sjogren P, Wardh I, Zimmerman M et al (2016) Oral care and mortality in older adults with pneumonia in hospitals or nursing homes: systematic review and meta-analysis. J Am Geriatr Soc 64:2109-2115. https://doi.org/10.1111/jgs. 14260

108. Abe S, Ishihara K, Adachi M et al (2008) Tongue-coating as risk indicator for aspiration pneumonia in edentate elderly. Arch Gerontol Geriatr 47:267-275. https://doi.org/10.1016/j.archg er.2007.08.005

109. Iinuma T, Arai Y, Abe $Y$ et al (2015) Denture wearing during sleep doubles the risk of pneumonia in the very elderly. J Dent Res 94:28s-36s. https://doi.org/10.1177/0022034514552493

110. Budtz-Jorgensen E, Mojon P, Rentsch A et al (2000) Effects of an oral health program on the occurrence of oral candidosis in a long-term care facility. Commun Dent Oral Epidemiol 28:141-149

111. Duyck J, Vandamme K, Krausch-Hofmann S et al (2016) Impact of denture cleaning method and overnight storage condition on denture biofilm mass and composition: a cross-over randomized clinical trial. PLoS One 11:e0145837. https://doi.org/10.1371/ journal.pone.0145837

112. Felton D, Cooper L, Duqum I et al (2011) Evidence-based guidelines for the care and maintenance of complete dentures: a publication of the American College of Prosthodontists. J Prosthodont 20:S1-s12. https://doi.org/10.1111/j.1532-849X.2010.00683.x

113. Sharif-Abdullah SS, Chong MC, Surindar-Kaur SS et al (2016) The effect of chlorhexidine in reducing oral colonisation in geriatric patients: a randomised controlled trial. Singapore Med J 57:262-266. https://doi.org/10.11622/smedj.2016091

114. Quintas V, Prada-Lopez I, Donos N et al (2015) Antiplaque effect of essential oils and $0.2 \%$ chlorhexidine on an in situ model of oral biofilm growth: a randomised clinical trial. PLoS One 10:e0117177. https://doi.org/10.1371/journal.pone.0117177

115. Liu C, Cao Y, Lin J et al (2018) Oral care measures for preventing nursing home-acquired pneumonia. Cochrane Database Syst Rev. https://doi.org/10.1002/14651858.cd012416.pub2

Publisher's Note Springer Nature remains neutral with regard to jurisdictional claims in published maps and institutional affiliations. 